\title{
Direct Medical Costs of Type 2 Diabetes in France: An Insurance Claims Database Analysis
}

\author{
Bernard Charbonnel $^{1} \cdot$ Dominique Simon $^{2} \cdot$ Jean Dallongeville $^{3} \cdot$ Isabelle Bureau $^{4}$. \\ Sylvie Dejager ${ }^{5} \cdot$ Laurie Levy-Bachelot $^{5} \cdot$ Julie Gourmelen $^{6} \cdot$ Bruno Detournay $^{4}$
}

Published online: 7 August 2017

(C) The Author(s) 2017. This article is an open access publication

\begin{abstract}
Objectives Our objects was to estimate the direct healthcare costs of type 2 diabetes mellitus (T2DM) in France in 2013.

Methods Data were drawn from a random sample of $\approx 600,000$ patients registered in the French national health insurances database, which covers $90 \%$ of the French population. An algorithm was used to select patients with T2DM. Direct healthcare costs from a collective perspective were derived from the database and compared with those from a control group to estimate the cost of diabetes and related comorbidities. Overall direct costs were also compared according to the diabetes therapies used throughout the year 2013.

Results Cost analysis was available for a sample of 25,987 patients with T2DM (mean age $67.5 \pm$ standard deviation
\end{abstract}

Electronic supplementary material The online version of this article (doi:10.1007/s41669-017-0050-3) contains supplementary material, which is available to authorized users.

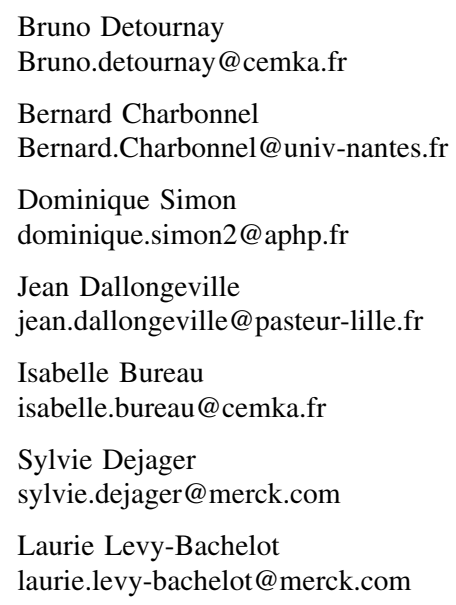

$12.5 ; 53.9 \%$ male) matched with a control group of 76,406 individuals without diabetes. Overall per patient per year medical expenditures were $€ 6506 \pm 10,106$ in the T2DM group as compared with $€ 3668 \pm 6954$ in the control group. The cost difference between the two groups was $€ 2838$ per patient per year, mainly due to hospitalizations, medication and nursing care costs. Total per capita annual costs were lowest for patients receiving metformin monotherapy (€4153 \pm 6170 ) and highest for those receiving insulin $(€ 12,890)$. However, apart from patients receiving insulin, costs did not differ markedly across the different oral treatment patterns.

Conclusion Extrapolating these results to the whole T2DM population in France, total direct costs of diagnosed T2DM in 2013 was estimated at over $€ 8.5$ billion. This estimate highlights the substantial economic burden of this condition on society.

Julie Gourmelen

julie.gourmelen@inserm.fr

1 Hôtel Dieu Hospital, Nantes, France

2 Diabetes Department and ICAN (Institute of

Cardiometabolism And Nutrition), Pitié Hospital, Paris, France

3 INSERM-U1167, Lille, France

4 Cemka-Eval, 43 Bd du Maréchal Joffre, 92340

Bourg-la-Reine, France

5 Merck Sharpe \& Dohme, Courbevoie, France

6 INSERM UMS 011, Villejuif, France 


\section{Key Points for Decision Makers}

In 2013, the average overall direct healthcare expenditure for a patient with type 2 diabetes mellitus (T2DM) in France was €6506.

The direct cost of diabetes and related morbidities was estimated at $€ 2838$ per patient per year.

Patients receiving insulin incurred the highest costs $(€ 12,890)$.

Costs did not differ markedly across the different oral treatment patterns.

\section{Introduction}

As in most Western countries, the prevalence of diabetes in France has risen sharply over the last two decades, reaching $4.7 \%$ of the adult general population in the French national survey conducted in 2013 [1] (updated to 5\% in 2015 [2]). Over 2009-2013, the growth rate of the diabetic population was estimated at $2.3 \%$ each year [2]. On this basis, it can be estimated that around 3.3 million people had diabetes in France at the beginning of 2015. The majority of these cases correspond to type 2 diabetes mellitus (T2DM), and this population continues to grow because of the aging population and lifestyle factors. In the 2007 ENTRED study [3], 92\% of all cases of diabetes were T2DM, and this proportion may have risen with the increases in obesity to reach $95 \%$ or more.

Given the large number of individuals affected and the high cost of managing the complications of diabetes, the economic burden from diabetes is considerable. Data from the 2007 ENTRED study provided an estimate of $€ 12.5$ billion for the total healthcare costs reimbursed by the National Sickness Fund for people with diabetes, whatever the type. However, this figure is likely to have evolved since then because of the increase in the treated population, the introduction of new treatments since 2007-notably glucagon-like peptide-1 (GLP-1) analogues and dipeptidylpeptidase-4 (DPP-4) inhibitors (gliptins) - and the impact of treatment guidelines recommending more intensive treatment regimens earlier in the disease course [4]. More recent estimates were also published by the National Sickness Fund, but these only considered reimbursed expenditure. The total healthcare costs reimbursed for people with diabetes was estimated at $€ 19$ billion in 2012. Several methods were then used to estimate the burden of diabetes, resulting in estimates varying between $€ 7.7$ billion and $€ 10$ billion [5].
Thus, we considered it timely to reassess the economic burden of T2DM in France. Recently, a number of public health insurance databases have become available in France, which have made it possible to collect quasi-exhaustive information on healthcare resource utilisation in representative samples of the French general population. The EGB (Echantillon Généraliste des Bénéficiaires) database is a representative sample of French National insurance funds that covers around 95\% of the French population [6]. This database has been used in several recent studies to document medication prescription, costs or outcomes in different disease groups in the French general population [7-9], including in patients with diabetes [10]. The objective of this study was to describe the characteristics of patients with T2DM in France and their treatments and to estimate their total direct healthcare expenditure as the cost directly related to diabetes care and related comorbidities.

Although some of the well-known diabetes drugs are modestly priced generics, new brand-name drugs continue to be introduced at higher prices. Their mechanisms of action differ: some induce fewer side effects and others have greater efficacy. It is therefore interesting to compare total direct costs according to the antidiabetic agents prescribed in a real-life setting. The cost of a drug is one criterion that may guide treatment choice among available glucose-lowering agents for a patient with T2DM [11, 12]. However, the cost of treatment alone does not reflect the budget consequences of the drug choice. Therefore, we were also interested in reporting hospital and community costs for different pharmacological therapy options (monotherapy, dual, other) and to use an example to illustrate how a simple comparison of the direct costs of diabetes treatment may result in misinterpretation.

\section{Methods}

This was a retrospective study of healthcare resource consumption and associated costs generated by a representative sample of patients with T2DM identified in the French general health insurance claims database in 2013. Direct healthcare costs were estimated from a collective perspective regardless of the institution or individual.

\subsection{The EGB Database}

The EGB (Echantillon Généraliste des Bénéficiaires) database is a random sample of beneficiaries of the principal French public health insurance scheme, which covers approximately $95 \%$ of the total French population (66 million individuals) [6]. The sample of 1/97 randomly selected individuals included in the EGB database 
corresponds to around 600,000 individuals. All information in the database is anonymous. The EGB database contains limited sociodemographic and medical data on healthcare users but comprehensive reimbursement records on healthcare consumption in community and hospital care. Sociodemographic information is restricted to age, sex, and place of residence. All items of medical consumption in the public or private sector that are eligible for reimbursement are documented, notably consultations, paraclinical tests, medication, devices and, since 2005, hospitalisations [6]. Items ineligible for reimbursement, such as over-thecounter drugs, are absent from the database and cannot be identified. In addition, information on inpatient rehabilitation is not available. For costing purposes, hospitalisations in acute care facilities (medicine, surgery or obstetrics) are coded in the EGB database through a specific diagnosisrelated group (DRG). Medication is identified in the database through the relevant Anatomical Therapeutic Chemical (ATC) classification code. Date of death is documented in the database but not the cause of death.

The only types of data in the EGB database associated with an explicit diagnosis are hospitalisation and eligibility for full insurance coverage due to a severe chronic disease (Affection de Longue Durée [ALD] status). In the case of hospitalisations, the diagnosis can be identified since each hospital stay is valued on the basis of a unique DRG, which is coded using the International Classification of Disease, tenth revision (ICD-10) codes [13]. The reasons for hospitalisation are coded either as primary diagnoses (PD; the condition for which the patient was hospitalised), related diagnoses (RD; any underlying condition that may have been related to the PD) or as associated diagnoses (AD; comorbidities that may affect the course or cost of hospitalisation). In the case of ALD status, eligible diseases are identified on a restrictive list established by the French public health insurance schemes that specifies the equivalent ICD-10 disease code.

\subsection{Subjects}

\subsubsection{Identification of Patients with T2DM}

Patients with diabetes were identified in the EGB database according to a criterion usually applied in France [14]. This criterion was EITHER reimbursement for three distinct prescriptions for antidiabetic medication (including insulin), or two prescriptions when large packs were delivered, on three different dates within 2 consecutive years or ALD status for diabetes. All adult patients (aged $\geq 18$ years) fulfilling this criterion during 2012 or 2013 were retained.

Additionally, a decision tree was used to distinguish patients with type 1 diabetes mellitus (T1DM) from those with T2DM (Fig. 1) [15]. This was based on hospitalisation

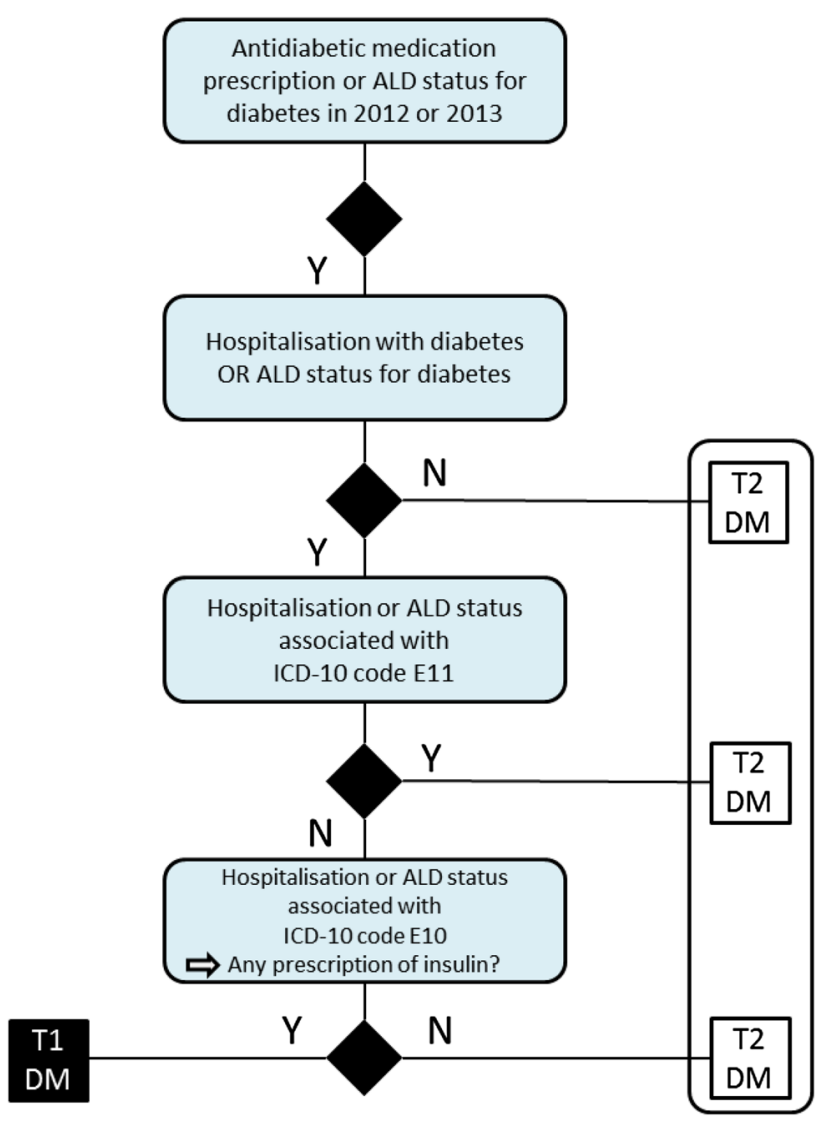

Fig. 1 Decision tree for identifying patients with T1DM and T2DM. $A L D$ affection de longue durée (full insurance coverage due to a severe chronic disease), ICD-10 International Classification of Diseases, tenth revision, $N$ no, TIDM type 1 diabetes mellitus, $T 2 D M$ type 2 diabetes mellitus, $Y$ yes

history with diabetes as an identified diagnosis (PD, RD or AD), ALD status for diabetes through the associated ICD10 code and insulin treatment history. The relevant ICD-10 codes for diabetes applied in this decision tree were E10 for T1DM and E11 for T2DM. We assumed that all patients with T1DM had an ALD status or were hospitalized at least once over a 2-year period for diabetes.

\subsubsection{Identification of Controls}

Beyond the cost of care for people with diabetes, the cost of diabetes care was estimated using a case-control approach [16, 17].

A control sample was built, matched for age, sex, and region of residence to the index diabetes case sample using the quota method. The overall demographic structure of the diabetes sample was determined and quotas allocated for each age, sex, and geographic area class. Subjects without diabetes were then selected randomly from the EGB database and assigned to each quota until three controls had been identified for each case in each age, sex, and geographic area class. 


\subsection{Data Collection}

For each eligible patient, information was extracted from the database on demographics (sex and age in 2013), ALD status for diabetes or other chronic diseases, and comorbidities or complications.

Comorbidities and complications of interest were ischaemic heart disease, stroke, cardiac failure, treated hypertension, treated dyslipidemia, kidney transplantation, chronic kidney failure, haemodialysis, retinopathy, hyperglycaemia, sleep apnoea and cancer. These were identified from three sources: hospitalisations in which these comorbidities were identified as a diagnosis through the relevant ICD-10 disease classification code, the presence of serial reimbursements for prescription of relevant specific medications, and ALD status identified through the relevant ICD-10 disease classification code.

All healthcare resource consumption documented in the EGB database between 1 January and 31 December 2013 were identified. Healthcare resource variables of interest were medication (for diabetes and other conditions) and other reimbursed pharmacy products, hospitalisations, consultations (specialists, general practitioners and dentists), paramedical care (nurses and physiotherapists), laboratory tests, medical devices, medical transport and other community care costs.

Costs presented for reimbursement were identified for each item in the EGB database. Ambulatory costs were directly estimated using reimbursement data from the EGB database. For hospitalisations, cost per DRG was estimated using the National Cost database per DRG [18]. All costs were estimated using a collective perspective (collective perspective limited to direct healthcare costs) according to the current guidelines for health economic evaluation in France [19].

\subsection{Statistical Analysis}

Two main analysis populations were considered in this study. For the description of the study population, all patients with T2DM identified in the EGB database were considered. For the cost analysis, patients with T2DM and controls who had died before the end of the cost assessment period (31 December 2013) were excluded to avoid bias due to differences in follow-up duration. A third population used to identify antidiabetic medication delivered during the last quarter of 2013 (the last period assessable in the study) was evaluated considering patients diagnosed with T2DM by the third quarter of 2013 at the latest.

Our presentation of the study population is principally descriptive. Continuous data are presented as mean values \pm standard deviation (SD) or as median values, and categorical data are presented as frequency counts and percentages. The occurrence of comorbidities and complications was compared between the diabetes cases and the matched controls using the Chi-squared $\left(\chi^{2}\right)$ test or Fisher's exact test as appropriate.

Costs were compared between cases and controls for each individual cost component and for total costs using the Mann-Whitney $U$ test. The differential cost between the cases and controls was calculated as a measure of the health economic burden of T2DM, including complications and related comorbidities. This burden was extrapolated to the whole French population using national diabetes prevalence data [1].

The cost of diabetes was reported for the different pharmacological therapy options (monotherapy, dual, other) according to hospital and community costs. Furthermore, an exploratory analysis of average annual consumption of care in patients with T2DM was conducted in patients receiving dual therapy throughout the year 2013 (quarters 1-4) depending on the type of dual therapy (metformin + DPP-4 inhibitor and metformin + sulfonylurea). For this analysis, patients treated with the same dual therapy throughout the year 2013 (same regimen during the quarters 1-4) were selected. Overall direct costs of healthcare were compared between the two groups.

As patients may have different characteristics according to their treatment group, we conducted an adjusted analysis (see Appendix I in the Electronic Supplementary Material [ESM]). A regression analysis (generalized linear model fitted with a Gamma distribution, after logarithmic transformation) was set up to explain the total healthcare consumption. Only patients who were treated throughout 2013 were analysed. The model took into account the following variables:

- Dual therapy in the last quarter of 2013: metformin + DPP-4 inhibitor or metformin + sulfonylurea

- Age in four groups $(<55,55-64,65-75, \geq 75$ years $)$

- Sex

- Presence of full coverage for a longstanding illness (ALD status)

- Simplified Charlson Comorbidity Index score based on diseases requiring hospitalizations in 2012-2013 (without taking into account patients age, which was already considered in the model)

- Patient area of residence

- Dual therapy duration (from the initial prescription of the dual therapy to the end of 2013).

All statistical analyses were performed using SAS software, version 9.2 (Cary, NC, USA). A bilateral probability threshold of 0.05 was used to determine statistical significance. 


\subsection{Ethical Considerations}

Since this was a retrospective study of an anonymised database and had no influence on patient care, ethics committee approval was not required.

\section{Results}

\subsection{Study Population}

Overall, 30,155 patients with diabetes were identified in the EGB database. After application of the decision tree rules, 28,708 (95.2\%) were considered to have T2DM. The majority of these patients $(N=23,182 ; 80.8 \%)$ were classified on the basis of an explicit ICD-10 code for T2DM associated with a hospitalisation record or ALD status; 5244 patients $(18.3 \%)$ were identified on the basis of a prescription for antidiabetic medication alone. Among this T2DM population, $19.4 \%$ were receiving insulin. After 2721 patients who had died by 31 December 2013 were excluded from the study population, 25,987 (90.5\%) remained for the cost analysis. The distribution of subjects across the analysis populations is presented in Fig. 2.

Overall, $54.1 \%$ of patients with T2DM were men, and the mean age of the sample was 67 years (Table 1). The majority $(74.4 \%)$ benefited from ALD status (full reimbursement of all related care) for their diabetes $(64 \%$ for $<6$ years), and $42.1 \%$ were classed as such for another pathology, most frequently hypertension $(N=3723$; $13.0 \%)$ and ischaemic heart disease $(N=1847 ; 6.4 \%)$.

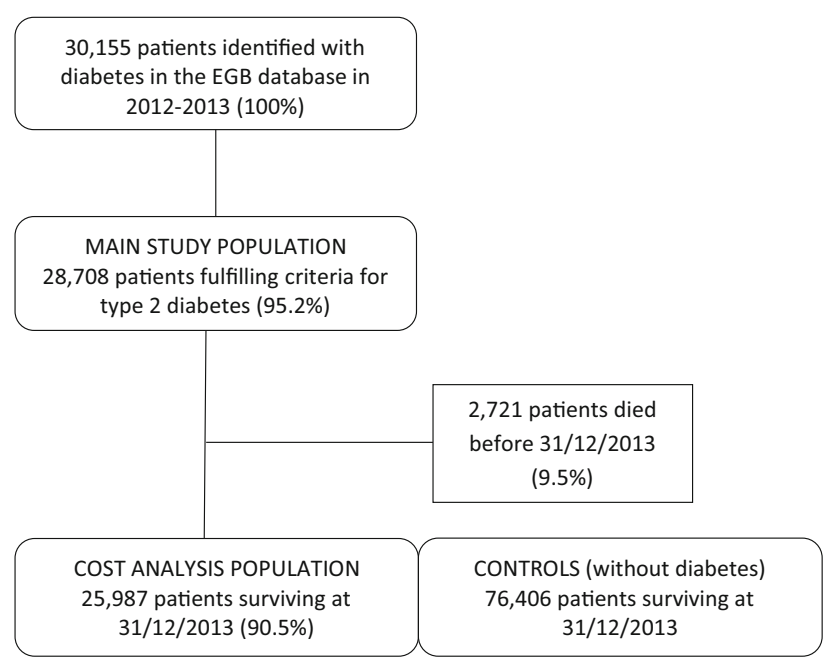

Fig. 2 Patient distribution and analysis populations. Percentages were calculated with respect to the previous line. EGB Echantillon Généraliste des Bénéficiaires database
Table 1 Study population demographics

\begin{tabular}{lll}
\hline Characteristic & $\begin{array}{l}\text { Main study } \\
\text { population } \\
(N=28,708)\end{array}$ & $\begin{array}{l}\text { Cost analysis } \\
\text { population } \\
(N=25,987)\end{array}$ \\
\hline Age (years) & $67.2 \pm 12.9$ & $67.3 \pm 12.5$ \\
Median (range) & $67(18-112)$ & $67(18-104)$ \\
$<45$ years & $1246(4.4)$ & $987(3.8)$ \\
Sex & $15,538(54.1)$ & $14,001(53.9)$ \\
Men $(\%)$ &
\end{tabular}

Data are presented as mean \pm standard deviation or $n(\%)$ unless otherwise indicated

\subsection{Comorbidities and Complications}

The 2013 prevalence of complications and comorbidities was analysed using the cost analysis population in both diabetes cases and controls (Table 2). The proportion of subjects with an ischaemic complication, heart failure, kidney disease or retinopathy or who were receiving medication for the treatment of hypertension or dyslipidemia was markedly higher for cases than for controls (Table 2). No difference was observed for all cancers combined, but the frequency of hepatobiliary cancers and pancreatic cancers was higher in cases, whereas the frequency of prostate cancers was higher in controls.

\subsection{Antidiabetic Medication}

Antidiabetic medication delivered during the last quarter of 2013 (the last period assessable in the study) was evaluated by class (Table 3 ) among patients diagnosed with T2DM by the third quarter of 2013 at the latest. Among the 27,829 patients with T2DM considered in this cross-sectional analysis, 3777 patients (13.6\%) had no medication delivered. Around half of the patients receiving treatment $(48.9 \%)$ were prescribed a monotherapy (including insulin monotherapy), principally metformin $(27.3 \%)$, and $25.6 \%$ were prescribed dual therapy. Insulin (alone or in combination) was prescribed for $19.4 \%$ of patients, and a GLP-1 analogue (alone or in combination) was prescribed for $3.5 \%$ of patients [20].

\subsection{Costs}

The total annual per capita cost incurred by patients with T2DM was $€ 6506$. These costs were 1.77 times higher than those incurred by the matched control group (€3668). The specific cost associated with T2DM and its related comorbidities or complications (difference between the two groups) was $€ 2838$ per patient per year (pppy). Ambulatory costs accounted for around two-thirds of costs, and hospital costs accounted for the remaining third 
Table 2 Comorbidities and complications in diabetes cases and controls

\begin{tabular}{|c|c|c|c|}
\hline Comorbidities and complications & Cases $(N=25,987)$ & Controls $(N=76,406)$ & $p$ value \\
\hline Ischaemic heart disease & $3160(12.2)$ & $4977(6.5)$ & $<0.0001$ \\
\hline Incident stroke in 2013 & $141(0.5)$ & $298(0.4)$ & 0.0011 \\
\hline \multicolumn{4}{|l|}{ Heart failure } \\
\hline ALD & $481(1.9)$ & $953(1.2)$ & $<0.0001$ \\
\hline Hospitalisation 2009-2013 main diagnosis & $851(3.3)$ & $983(1.3)$ & $<0.0001$ \\
\hline Hospitalisation 2009-2013, secondary diagnosis & $332(1.3)$ & $449(0.6)$ & $<0.0001$ \\
\hline Either ALD or hospitalisation & $1471(5.7)$ & $2068(2.7)$ & $<0.0001$ \\
\hline Treated hypertension in 2013 & $20,192(77.7)$ & $36,773(48.1)$ & $<0.0001$ \\
\hline Treated dyslipidemia in 2013 & $15,441(59.4)$ & $21,853(28.6)$ & $<0.0001$ \\
\hline Kidney transplantation in 2013 & $2(<0.1)$ & $2(<0.1)$ & 0.2681 \\
\hline Chronic kidney disease & $249(1.0)$ & $415(0.5)$ & $<0.0001$ \\
\hline Haemodialysis ( $\geq 45$ sessions per year) & $118(0.5)$ & $96(0.1)$ & $<0.0001$ \\
\hline Terminal kidney disease & $120(0.5)$ & $98(0.1)$ & $<0.0001$ \\
\hline Retinal laser treatment in 2013 & $87(0.3)$ & $28(<0.1)$ & $<0.0001$ \\
\hline Retinopathy in 2013 & $609(2.3)$ & $734(1.0)$ & $<0.0001$ \\
\hline \multicolumn{4}{|l|}{ Hypoglycaemia } \\
\hline In 2013 & $162(0.6)$ & - & $<0.0001$ \\
\hline Between 2009 and 2013 & $477(1.8)$ & $3(<0.1)$ & $<0.0001$ \\
\hline \multicolumn{4}{|l|}{ Sleep apnoea } \\
\hline Hospitalisation in 2013 & $581(2.2)$ & $485(0.6)$ & $<0.0001$ \\
\hline Reimbursement for CPAP in 2013 & $1470(5.7)$ & $1587(2.1)$ & $<0.0001$ \\
\hline Either hospitalisation or CPAP in 2013 & $1732(6.7)$ & $1835(2.4)$ & $<0.0001$ \\
\hline Cancer & $3174(12.2)$ & $9000(11.8)$ & 0.0615 \\
\hline Prostate & $593(18.7)$ & $1964(21.8)$ & 0.0002 \\
\hline Breast & $523(16.5)$ & 1595 (17.7) & 0.1118 \\
\hline Colon & $237(7.5)$ & $622(6.9)$ & 0.2931 \\
\hline Bladder & $206(6.5)$ & $521(5.8)$ & 0.1517 \\
\hline Lung & $131(4.1)$ & $353(3.9)$ & 0.6112 \\
\hline Other skin cancers & $126(4.0)$ & $359(4.0)$ & 0.9622 \\
\hline Rectum & $99(3.1)$ & $231(2.6)$ & 0.0994 \\
\hline Liver or biliary cancer & $68(2.1)$ & $71(0.8)$ & $<0.0001$ \\
\hline Kidney & $87(2.7)$ & $232(2.6)$ & 0.6206 \\
\hline Mouth & $71(2.2)$ & $200(2.2)$ & 0.9615 \\
\hline Pancreas & $54(1.7)$ & $54(0.6)$ & $<0.0001$ \\
\hline Thyroid & $68(2.1)$ & $160(1.8)$ & 0.1926 \\
\hline Melanoma & $70(2.2)$ & $180(2.0)$ & 0.4829 \\
\hline
\end{tabular}

Data are presented as $n(\%)$ unless otherwise indicated

$A L D$ Affection de Longue Durée, $C P A P$ continuous positive airway pressure

(Table 4). The highest individual costs incurred related to hospitalisations $(33.2 \%$ of total cost), medications $(23.7 \%)$ and nursing care $(10.9 \%)$. For each individual cost component, expenditure for diabetes cases was significantly higher $(p<0.0001)$ than for controls by a factor ranging from 1.2-fold (for physician consultations, interventions and physiotherapy) to fourfold (for nursing costs).
Costs were reported between the principal therapeutic patterns delivered in the last quarter of 2013 (Fig. 3). Total per capita annual costs were lowest in patients receiving metformin monotherapy $(€ 4153 \pm 6170)$ and highest in those receiving insulin $(€ 12,890 \pm 14,735)$. However, apart from patients receiving insulin, costs did not differ markedly across the different treatment patterns. 
Table 3 Medications delivered during last quarter of 2013

\begin{tabular}{ll}
\hline Treatment & $N=27,829$ \\
\hline No documented treatment & 3777 \\
Monotherapy & \\
Metformin & $6568(27.3)$ \\
Sulphonylurea & $2120(8.8)$ \\
Other & $1228(5.1)$ \\
Dual therapy & \\
Metformin + sulphonylurea & $2381(9.9)$ \\
Metformin + DPP-4 inhibitor & $2399(10.0)$ \\
Sulphonylurea + DPP-4 inhibitor & $431(1.8)$ \\
Other & $943(3.9)$ \\
Triple therapy & \\
Metformin + sulphonylurea + DPP-4 inhibitor & $2019(8.4)$ \\
Other & $1031(4.3)$ \\
Other multi-therapies, excluding insulin & $243(1.0)$ \\
Insulin regimens & \\
Insulin alone & $1864(7.7)$ \\
Insulin + metformin & $741(3.1)$ \\
Insulin + DPP-4 inhibitor & $91(0.4)$ \\
Insulin + metformin + DPP-4 inhibitor & $247(1.0)$ \\
Insulin + sulphonylurea & $131(0.5)$ \\
Other & $1615(6.7)$ \\
\hline
\end{tabular}

Data are presented as $n(\%)$ unless otherwise indicated. Percentages are calculated with respect to the 24,052 patients with a documented treatment

$D P P-4$ dipeptidylpeptidase-4

\subsection{Costs According to Treatment Pattern: Patients Treated with Dual Therapy}

A specific analysis of average annual consumption of care in patients with T2DM was conducted in patients receiving dual therapy throughout the year 2013 (quarters 1-4), comparing patients treated with metformin + DPP-4 inhibitor $(N=1846)$ and those receiving metformin + sulfonylurea $(N=1811)$.

In the real-life setting, the average cost of dual therapy with metformin + a DPP-4 inhibitor was estimated at $€ 605$ pppy (all taxes included), and the average cost of dual therapy with metformin + a sulfonylurea was estimated at $€ 270$ pppy, a significant difference of $€ 335$ pppy $(p<0.0001,+124 \%)$.

When considering average overall direct healthcare costs, the gap between patients treated with metformin + a DDP-4 inhibitor and those treated with metformin + a sulfonylurea reduced to $€ 167$ per year $(p<0.0001 ;+4 \%)$. The difference in costs for hypoglycaemic agents was partially offset by the reduced need for paramedics $(p=0.0131)$, including nursing $(p=0.0004)$, and a nonsignificant reduction in inpatient costs $(p=0.1436)$ (Table 5).

Finally, patients treated throughout 2013 with metformin + a DPP-4 inhibitor were younger than those treated with metformin + a sulfonylurea $(65.0 \pm 10.6$ vs. $67.7 \pm 11.0$ years; $p<0.0001)$; their geographical distribution $(p<0.0001)$ and ALD status coverage ( 83 vs. $86 \%$,
Table 4 Per capita costs presented for reimbursement by diabetes cases and controls

\begin{tabular}{llll}
\hline Costs & Cases $(N=25,987)$ & Controls $(N=76,406)$ & $p$ value \\
\hline Hospital costs & $2159(33.2) \pm 6502$ & $1304(35.5) \pm 4632$ & $<0.0001$ \\
Ambulatory costs & $1541(23.7) \pm 2057$ & $731(19.9) \pm 1693$ & $<0.0001$ \\
Medication & $233(3.6) \pm 213$ & $191(5.2) \pm 198$ & $<0.0001$ \\
Physician consultations & $58(0.9) \pm 159$ & $33(0.9) \pm 110$ & $<0.0001$ \\
Home visits & $319(4.9) \pm 735$ & $275(7.5) \pm 634$ & $<0.0001$ \\
Interventions & $712(10.9) \pm 2468$ & $182(4.9) \pm 1120$ & $<0.0001$ \\
Nursing care & $150(2.3) \pm 506$ & $122(3.3) \pm 420$ & $<0.0001$ \\
Physiotherapy & $583(8.9) \pm 1146$ & $309(8.4) \pm 744$ & $<0.0001$ \\
Medical devices & $145(2.2) \pm 489$ & $179(4.9) \pm 556$ & $<0.0001$ \\
Dental care & $201(3.1) \pm 247$ & $119(3.2) \pm 191$ & $<0.0001$ \\
Laboratory tests & $236(3.6) \pm 1325$ & $107(2.9) \pm 612$ & $<0.0001$ \\
Transportation & & & $<0.0001$ \\
Total ambulatory costs & $4347(66.8) \pm 5230$ & $2364(64.5) \pm 3421$ & $<0.0001$ \\
Total community costs & $6506(100) \pm 9955$ & $3668(100) \pm 6854$ & \\
Total costs & $3093(1627-7069)$ & $1530(665-558)$ & \\
Median (IQR) &
\end{tabular}

Costs are presented in $€$, year 2013 values, as mean $(\%) \pm$ standard deviation unless otherwise indicated $I Q R$ interquartile range, $S D$ standard deviation 
Fig. 3 Per capita annual costs by patients with diabetes according to the principal therapeutic patterns (last 2013 quarter only). The numbers at the end of the horizontal columns represent total costs, the filled bars hospital costs and the open bars community costs. DPP-4-I inhibitor of dipeptidylpeptidase-4, $S U$ sulphonylurea

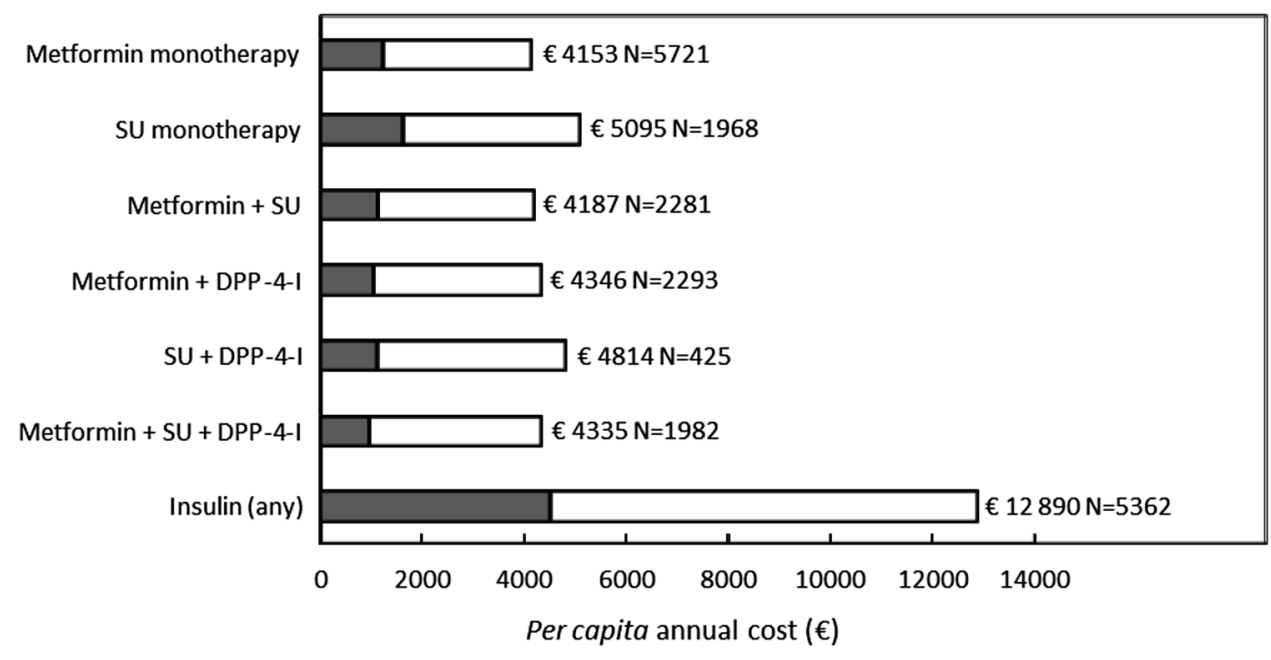

Table 5 Per capita costs presented for reimbursement per dual therapy (entire year)

\begin{tabular}{|c|c|c|c|}
\hline Costs per item per year & $\begin{array}{l}\text { Patients treated with } \\
\text { metformin }+ \text { a sulfonylurea }\end{array}$ & $\begin{array}{l}\text { Patients treated with metformin } \\
+ \text { a DPP-4 inhibitor }\end{array}$ & $p$ value \\
\hline$N$ & $1811(100.0)$ & $1846(100.0)$ & \\
\hline Total amount presented for reimbursement & $3969 \pm 5337$ & $4136 \pm 5693$ & $<0.0001$ \\
\hline Hospitalisations & $1002 \pm 3228$ & $917 \pm 3270$ & 0.1436 \\
\hline \multicolumn{4}{|l|}{ Ambulatory care } \\
\hline Medications & $1181 \pm 1697$ & $1542 \pm 1998$ & $<0.0001$ \\
\hline Hypoglycaemic agents & $605 \pm 231$ & $270 \pm 204$ & $<0.0001$ \\
\hline Medical fees & $660 \pm 847$ & $633 \pm 777$ & 0.1561 \\
\hline Paramedics & $373 \pm 1476$ & $257 \pm 1024$ & 0.0131 \\
\hline Nursing care & $262 \pm 1344$ & $143 \pm 815$ & 0.0004 \\
\hline Medical devices & $353 \pm 693$ & $352 \pm 724$ & 0.2466 \\
\hline Transportation & $91 \pm 494$ & $99 \pm 764$ & 0.0003 \\
\hline Laboratory tests & $164 \pm 160$ & $165 \pm 166$ & 0.3762 \\
\hline Dental care & $138 \pm 479$ & $162 \pm 499$ & 0.0013 \\
\hline
\end{tabular}

Costs are presented in $€$, year 2013 values as $N(\%)$ or mean \pm standard deviation

$D P P-4$ dipeptidylpeptidase-4

$p=0.0052$ ) also differed, and these results suggest the two populations are not strictly comparable in a real-life setting. Therefore, we used a multivariate regression model to compare costs according to the dual therapy prescribed during 2013 as described in the methodology: analyses were adjusted on age, sex, a simplified Charlson Comorbidity Index score, ALD status and area of residence (Appendix 1 in the ESM).

The adjusted average overall healthcare costs of patients treated with metformin + a DPP-4 inhibitor were $6.3 \%$ (95\% confidence interval [CI] $0.4-12.6 \%$ ) higher than the average overall healthcare costs of patients treated with metformin + a sulfonylurea in $2013(p=0.0348)$. Goodness of fit of the adjusted model was estimated to be acceptable $\left(\chi^{2}\right.$ statistic [or the deviance] divided by the degrees of freedom was 0.82 ).
No significant difference in hospitalisations was observed between the groups of patients treated with a dual therapy $(p=0.98)$. Although using a DPP-4 inhibitor was more expensive, this was partly offset by reduced medical fees (honoraria) $(-5.8 \% ; p=0.04)$ and need for paramedics $(-25.5 \% ; p<0.0001)$ in patients treated with metformin + a DPP-4 inhibitor.

\section{Discussion}

In this study, we analysed direct healthcare costs accrued by patients with T2DM in 2013 from a collective perspective using a bottom-up approach in a representative sample of the national health insurance claims database (EGB). A sample of 28,708 patients fulfilling criteria for 
T2DM using a decision tree was identified. Both selection and classification algorithms used in this study have their own limitations. The selection process excluded the least severe cases (without both antidiabetic medication and ALD status). The classification algorithm is likely to be imperfect. However, this will have only a marginal impact on the quality of the results.

Direct costs identified were those figuring in the national health insurance database. Some costs supported by patients and their families were not considered, such as some over-the-counter drugs. However, such costs are usually considered to be very low [21], especially for patients with diabetes who have $100 \%$ reimbursement status or are covered by a supplementary mutual health insurance.

The cost analysis was performed for all patients alive at 31 December 2013 and thus took into account expenditure for a full 12-month period. The mean annual per capita cost accrued by patients with T2DM was €6506, which was nearly twice as high as that of a matched sample of control subjects without diabetes. These data can be compared with a previous estimate of the cost of T2DM in France determined in the 2007 ENTRED survey [22], which was $€ 4890$ $(€ 10,413$ in patients treated with insulin and $€ 3625$ in patients not using insulin). The costs of diabetes would thus have increased by 30\% between 2007 and 2013. This increase concerned all individual cost components. However, differences in methodologies between the two studies may introduce bias in the comparison (i.e. costing in the ENTRED survey was not conducted using the methodological guidelines for economic evaluation published in 2012 [19]; as an example, hospital stays were valuated using tariffs and not costs, and the cost perspective was that of the National Sickness Fund).

We observed little change in the pattern of antidiabetic medication use since the 2007 ENTRED study [23], with the exception of the appearance of a significant proportion of patients receiving a DPP-4 inhibitor, which reached $25.3 \%$ in 2013 . This was accompanied by a fall in prescriptions for sulphonylureas, from 49 to $30 \%$. The proportion of patients receiving insulin remained stable at $19 \%$, and the proportion of patients receiving monotherapy with an oral antidiabetic drug was also stable, at $42 \%$. The use of metformin increased.

Patients with diabetes generated an additional per capita cost of $€ 2838$ compared with the matched controls in 2013. This cost represents both the cost of T2DM care and the costs of diabetes-related comorbidities and complications. Extrapolated to the estimated total French population with treated T2DM of nearly 3 million individuals (4.7\%), this represents a total annual cost of $€ 8.5$ billion, corresponding to around $5 \%$ of all healthcare expenditure in France (estimated at $€ 186.7$ billion in 2013 [24]). The overall healthcare expenditure for people with diabetes reaches $€ 19.5$ billion. Such results were remarkably close to those of de Lagasnerie et al. [5] despite methodological differences (e.g. this study considered both T1DM and T2DM, and estimates are based on 2012 reimbursed expenditures only).

The diabetes burden is likely to have increased since 2013, mainly due to the rising prevalence (in France, the average annual increase in diabetes prevalence was $+2.3 \%$ between 2009 and 2013 [2]). A series of pricing measures has limited the pace of price increase.

In general, patients with diabetes tended to be more ill than controls, with significantly higher rates of a broad range of comorbidities. Furthermore, as the analysis considered only patients who did not die during the year, estimates provided in Table 2 may underestimate the full burden of these comorbidities. As such, it is interesting that the two most frequent reasons for hospitalisation for patients with diabetes were haemodialysis and cancer chemotherapy. Both kidney disease in general and regular haemodialysis ( $\geq 45$ sessions/year) in particular were more frequent in diabetes cases than in controls, consistent with the well-characterised renal complications of diabetes [25]. On the other hand, although certain cancers were more frequent in diabetes cases (hepatobiliary and pancreatic cancers), the most frequent cancer type, prostate cancer, was in fact more frequent in controls. Again, this is consistent with the known association of these cancers with diabetes [26].

Excluding patients who died during the study period may have introduced a bias. Some evidence suggests that patients at the end of life drive healthcare spending, but this remains controversial [27]. Conversely, regardless of the period considered (year, month, etc.), including the costs of people who died early in the period would underestimate the costs of illness. Finally, we consider that end-of-life care is an important and challenging issue that needs to be addressed independently. A specific study on the cost of care at the end of life among people with diabetes is necessary.

The largest individual cost components were related to hospitalisations, medications and nursing care. This raises many questions, both about the organisation of care and about medication prescribing practices in France.

With regards to the healthcare system, it is well known that patients with diabetes in France are often referred to hospital even for issues that could be managed in an ambulatory setting. In the French Healthcare system, private nursing care is often used to provide an answer to social and medical issues encountered by patients with diabetes.

In our analysis, medication costs included those related both to antidiabetic therapy and to other drugs that may be prescribed to treat comorbidities or related cardiovascular 
risk factors. In the USA [28], the cost of antidiabetic agents and diabetes supplies was estimated to represent $12 \%$ of the total direct medical costs, and prescription medications for the complications of diabetes or comorbidities was estimated at $18 \%$. In France, $23.7 \%$ of diabetes costs are related to medications. However, when comparing the costs of antidiabetic agents, it is interesting to consider not only the price of drugs but also the budget impact of total care associated with the use of the drug. Our analysis provides an exploratory illustration of this based on a cost analysis of two dual therapies. The yearly cost of dual therapy with metformin + a DPP-4 inhibitor appears to be more than double that of metformin + a sulfonylurea when considering only the costs of the antidiabetic therapy. This estimate may be debatable because it was based on the public price of drugs, all taxes included, in France in 2013. Unknown rebates and paybacks are negotiated between payers and pharmaceutical companies for licensed drugs, resulting in lower prices in practice. However, considering the overall annual healthcare expenditure, the adjusted difference among the two populations was only $6 \%$ in 2013. Higher costs of treatment are partially offset by savings on other cost items.

Health-related retrospective databases, particularly claims databases, continue to be an important data source for outcomes research. A search of PubMed ((claims analysis[MeSH Terms]) OR (Claims[Title/Abstract]) AND ("2015/01/01”[Date-MeSH] : “2015/12/31”[Date$\mathrm{MeSH}])$ ) indicated that analyses of insurance claims data were published in at least 500 articles in 2015. In France, EGB contains exhaustive information on reimbursement claims for a representative sample of the national health insurance database covering 95\% of the French population. Nevertheless, like other databases, EGB has some limitations: diagnoses rely on algorithms instead of adjudicated events, some patient subgroups, such as students and civil servants, are not well represented in the database; diagnoses are only documented if the patient was hospitalised or eligible for full reimbursement for an ALD. Other limitations include the absence of information on medications, tests or interventions that were prescribed but never delivered; limited documentation of sociodemographic and clinical characteristics of the insuree; and the risk of incomplete or inaccurate coding of medical events.

\section{Conclusion}

This insurance claims database study estimated the total cost of T2DM (including related comorbidities and complications) in France in 2013 to be $€ 8.5$ billion, corresponding to $5 \%$ of total public expenditure on healthcare. This large economic burden from diabetes highlights the importance of public health programmes aimed at reducing the incidence of T2DM through the promotion of healthy lifestyles and at the prevention of diabetic complications (better glycaemic control, less therapeutic inertia and better compliance with lifestyle measures and drugs) and of developing integrated care programmes for patients with diabetes that may be less costly for society.

Author Contributions BC, SD and LLB conceptualized the study idea. BD designed the study, developed the data analysis plan and provided critical feedback at the design stage, wrote the first version of the manuscript, and is the guarantor of the study. IB performed all the analyses. All authors critically reviewed the manuscript and approved the final version.

\section{Compliance with Ethical Standards}

Data Availability Statement Data that supported these analyses are available from Dr. Bruno Detournay.

Funding MSD France provided funding for this project.

Conflict of interest IB and BD are employed by Cemka-Eval, a contract research organisation that was contracted by MSD France for this study. BD has also received honoraria for consultancy from MSD, Novo-Nordisk, Sanofi. LLB and SD are employed by MSD France. $\mathrm{BC}$, DS and JD have received honoraria from MSD France for participating on the scientific board for this study. BC has also received honoraria for consultancy from AstraZeneca, Boehringer-Ingelheim, Janssen Pharmaceuticals, Eli Lilly, MSD, Novartis, Novo-Nordisk and Sanofi. DS has served as an expert for Sanofi Aventis and Takeda and has been a member of a board for Astellas, MSD and Novartis, and received fees for all these activities. JG has no conflicts of interest.

Open Access This article is distributed under the terms of the Creative Commons Attribution-NonCommercial 4.0 International License (http://creativecommons.org/licenses/by-nc/4.0/), which permits any noncommercial use, distribution, and reproduction in any medium, provided you give appropriate credit to the original author(s) and the source, provide a link to the Creative Commons license, and indicate if changes were made.

\section{References}

1. Mandereau-Bruno L, Denis P, Fagot-Campagna AF, Fosse-Edorh $S$. Prévalence du diabète traité pharmacologiquement et disparités territoriales en France en 2012. Bull Epidémiol Hebd. 2014;30-31:493-9.

2. Santé Publique France. Prévalence et incidence du diabète. http:// invs.santepubliquefrance.fr/Dossiers-thematiques/Maladieschroniques-et-traumatismes/Diabete/Donnees-epidemiologiques/ Prevalence-et-incidence-du-diabete. Accessed 7 Feb 2017.

3. Druet C, Roudier C, Romon I, Assogba F, Bourdel-Marchasson I, Eschwege ER-F, M., et al. Échantillon national témoin représentatif des personnes diabétiques, Entred 2007-2010. Caractéristiques, état de santé, prise en charge et poids économique des personnes diabétiques. Saint-Maurice: Institut de veille sanitaire, 2012. 
4. Nathan DM, Buse JB, Davidson MB, Ferrannini E, Holman RR, Sherwin R, et al. Medical management of hyperglycemia in type 2 diabetes: a consensus algorithm for the initiation and adjustment of therapy: a consensus statement of the American Diabetes Association and the European Association for the Study of Diabetes. Diabetes Care. 2009;32(1):193-203.

5. de Lagasnerie G, Aguadé AS, Denis P, Fagot-Campagna A, Gastaldi-Menager C. The economic burden of diabetes to French national health insurance: a new cost-of-illness method based on a combined medicalized and incremental approach. Eur J Health Econ. doi:10.1007/s10198-017-0873-y (Epub: 11 Feb 2017).

6. Tuppin P, de Roquefeuil L, Weill A, Ricordeau P, Merlière Y. French national health insurance information system and the permanent beneficiaries sample. Rev Epidemiol Santé Publique. 2010;54(4):286-90.

7. Dupouy J, Fournier JP, Jouanjus E, Palmaro A, Poutrain JC, Oustric S, et al. Baclofen for alcohol dependence in France: incidence of treated patients and prescription patterns-a cohort study. Eur Neuropsychopharmacol. 2014;24(2):192-9.

8. Fautrel B, Cukierman G, Joubert JM, Laurendeau C, Gourmelen J, Fagnani F. Healthcare service utilisation costs attributable to rheumatoid arthritis in France: analysis of a representative national claims database. Joint Bone Spine. 2016;83(4):461-2.

9. Vorilhon C, Chenaf C, Mulliez A, Pereira B, Clerfond G, Authier $\mathrm{N}$, et al. Heart failure prognosis and management in over-80year-old patients: data from a French national observational retrospective cohort. Eur J Clin Pharmacol. 2015;71(2):251-60.

10. Detournay B, Halimi S, Robert J, Deschaseaux C, Dejager S. Hypoglycemia hospitalization frequency in patients with type 2 diabetes mellitus: a comparison of dipeptidyl peptidase 4 inhibitors and insulin secretagogues using the French health insurance database. Vasc Health Risk Manag. 2015;11:417-25.

11. Inzucchi SE, Bergenstal RM, Buse JB, Diamant M, Ferrannini E, Nauck M, Peters AL, Tsapas A, Wender R, Matthews DR. Management of hyperglycaemia in type 2 diabetes: a patientcentered approach. Position statement of the American Diabetes Association (ADA) and the European Association for the Study of Diabetes (EASD). Diabetologia. 2012;55(6):1577-96.

12. Inzucchi SE, Bergenstal RM, Buse JB, Diamant M, Ferrannini E, Nauck M, Peters AL, Tsapas A, Wender R, Matthews DR. Management of hyperglycaemia in type 2 diabetes: a patientcentered approach. Update to a position statement of the American Diabetes Association and the European Association for the Study of Diabetes. Diabetes Care. 2015;38(1):140-9.

13. World Health Organization. International classification of diseases 10th revision. 4th ed. Geneva: WHO; 2010.
14. Caisse Nationale de l'Assurance Maladie des Travailleurs Salariés. Rapport au ministre chargé de la Sécurité sociale et au Parlement sur l'évolution des charges et des produits de l'Assurance Maladie. 2014.

15. Quantin C, CNAMTS. Etude des algorithmes de définition de pathologies dans le système national d'information inter-régimes de l'assurance maladie (SNIIRAM). 2014.

16. Jönsson B. The economic impact of diabetes. Diabetes Care. 1998;21(Suppl 3):C7-10.

17. Williams R. Estimating the national and global costs of diabetes. Diabetes Res Clin Pract. 2016;119:118-20.

18. Echelle Nationale des coûts. ENCC. http://www.atih.fr.

19. HAS. Guide méthodologique. Choix méthodologiques pour l'évaluation économique à la HAS. Octobre 2011. http://www. has-sante.fr/.

20. Simon D, Dallongeville J, Charbonnel B, Bureau I, Detournay B, Leproust S, Levy-Bachelot L, Gourmelen J. Patterns of pharmacological treatment in type 2 diabetes in france in 2013 Poster PDB14. ISPOR 18th Annual European Congress, 7-11 November $2015 \mathrm{MiCo}$-Milano Congressi, Milan, Italy.

21. French Health Ministry. Direction de la recherche, des études, de l'évaluation et des statistiques. Les dépenses de santé en 2015. Résultats des comptes de la santé. Edition 2016, République Française.

22. Ricci P, Chantry M, Detournay B, Poutignat N, Kusnik-Joinville $\mathrm{O}$, Raimond V, et al. Coût des soins remboursés par l'Assurance maladie aux personnes traitées pour diabète : Etudes Entred 2001 et 2007. Bull Epidemiol Hebd. 2009;42-43:464-9.

23. Robert J, Roudier C, Poutignat N, Fagot-Campagna A, Weill A, Rudnichi A, et al. Prise en charge des personnes diabétiques de type 2 en France en 2007 et tendances par rapport à 2001. Bull Epidémiol Hebd. 2009;42-43:455-60.

24. Comptes nationaux de la santé. Consommation de soins et biens médicaux. DREES. 2013.

25. Detournay B, Simon D, Guillausseau PJ, Joly D, Verges B, Attali C, et al. Chronic kidney disease in type 2 diabetes patients in France: prevalence, influence of glycaemic control and implications for the pharmacological management of diabetes. Diabetes Metab. 2012;38(2):102-12.

26. Tsilidis KK, Kasimis JC, Lopez DS, Ntzani EE, Ioannidis JP. Type 2 diabetes and cancer: umbrella review of meta-analyses of observational studies. BMJ. 2015;350:g7607.

27. Aldridge M, Kelley AS. The myth regarding the high cost of endof-life care. Am J Public Health. 2015;105(12):2411-5.

28. American Diabetes Association. Economic costs of diabetes in USA in 2012. Diabetes Care. 2013;36(4):1033-46. 